\title{
Research of vibration resistance of non-rigid shafts turning with various technological set-ups
}

\author{
Sergey L. Vasilevykh ${ }^{1, *}$, and Evgeniy S. Shelihov ${ }^{2}$ \\ ${ }^{1}$ Vyatka State University, Kirov, Russian Federation \\ ${ }^{2}$ Orenburg State University, Orenburg, Russian Federation
}

\begin{abstract}
The article considers the definition of the stability range of a dynamic system for turning nonrigid shafts with different technological set-ups: standard and developed ones; they are improved as a result of this research. The topicality of the study is due to the fact that processing such parts is associated with significant difficulties caused by deformation of the workpiece under the cutting force as well as occurrence of vibration of the part during processing, they are so intense and in practice they force to significantly reduce the cutting regime, recur to multiple-pass operation, lead to premature deterioration of the cutter, as a result, reduce the productivity of machining shafts on metal-cutting machines. In this connection, the purpose of the present research is to determine the boundaries of the stability regions with intensive turning of non-rigid shafts. In the article the basic theoretical principles of construction of a mathematical system focused on the process of non-free cutting of a dynamic machine are justified. By means of the developed mathematical model interrelations are established and legitimacies of influence of various technological set-ups on stability of the dynamic system of the machine-tool-device-tool-blank are revealed. The conducted researches allow to more objectively represent difficult processes that occur in a closed dynamic system of a machine.
\end{abstract}

\section{Introduction}

The components with rotation bodies account for $30 \%$ of all the machine components. It is the most labour consuming to make the details characterized by fragility: all kinds of shafts, torsion bars, shafts, stems, leading cylinders, nonrigid shafts, etc.

Non-rigid shafts are the ones with length-to-diameter ( $\mathrm{L}$ to $\mathrm{D})$ rate is over $12(\mathrm{~L} / \mathrm{D}>12)$. Due to fragility of the processed non-rigid shaft the technological system machine-device-tool-blank is pliable to the influence of external transverse force and dynamic factors of the cutting process [1].

Processing such components is quite difficult due to the fact that a processed component gets deformed during cutting and to vibration in the component during processing. These factors can be so strong that the cutting regime is to be reduced or multiple-pass operation is to be used, they cause decrease in firmness and operational life of the cutting instrument. [2-7]. Vibrations are not wanted at finish process with cutting at shall depth, when non-vibration movement of the component and the cutter in the cutting zone can lead to defective goods.

The problem of vibration is topical at metalprocessing with the help of $\mathrm{CNC}$ machines, as it leads not just to decrease in processing accuracy: vibrations in the cutting zone can also lead to accelerated amortization of the machine.
At the same time uncontrolled mechanical oscillations with a comparatively big amplitude are a limiting factor for increasing productivity of cutting process $[8,9]$. And oscillations appear due to presence and mutual influence of technological cutting conditions, external perturbing forces and parameters of the elastic system of a manufacturing lathe. That's why a decrease in efficiency of non-rigid shafts processing depends mainly on providing the conditions of processing stability.

Nowadays stability is understood according to the experience of the technologist. The existing methods do not provide accuracy, as the mathematical models used for its calculations are oversimplified. Coping with this research issue successfully depends not only on the traditional ways, but also on availability of necessary mathematical models that are able to describe the interdependence of vibrations of the elastic system of the machine and the dynamic process of cutting.

Thus the aim of the research is to work out a mathematical model by meas of which it is possible to calculate the limits of stability zones at linear turning of non-rigid shafts for different kinds of technological equipment of a turning lathe.

The tasks are the following:

1. To work out the methods of researching the mathematical model as for vibration-resistance at linear turning of non-rigid shafts;

\footnotetext{
Corresponding author: shelevgen@mail.ru
} 
2. To get a characteristic equation in order to realize the mathematical model of vibration-resistance;

3. To determine the stability zones of the dynamic system under research at lathe work of non-rigid shafts with different technological equipment.

\section{Materials and Methods}

In the research materials and methods of cutting theory, structural resistance, mathematical modeling were used. The research of influence of various technological equipment of turning lathes on vibration-resistance was fulfilled by the methods of serial presence detection of the parameters of the worked out mathematical model.

\subsection{Mathematical modeling of vibration- resistance of linear turning of non-rigid shafts}

To calculate the resistance of the dynamic system in question let us consider the analytical model (Pic. 1).

Let us assume that the shaft vibrates in plane that goes through the symmetry axis of the processed shaft.

In the cutting area of the analytical model there is a support attachment group of the processed shaft.

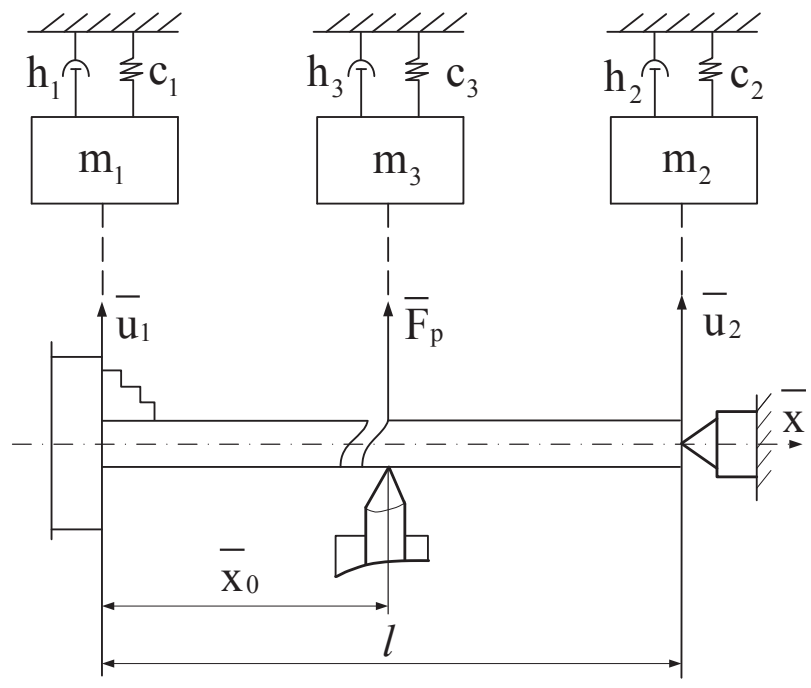

Fig. 1. The analytical model of calculating the stability zone of the dynamic system under research

The analytical model shows: equivalent mass $\mathrm{m}_{\mathrm{i}}$, damping $h_{i}$, rigidity of bearings in the sections $\mathrm{Ci}$, where $\mathrm{i}=1 \ldots 3$, shaft length 1 , coordinate of the cutter application $\bar{x}_{0}$, cutting power $\bar{F}_{p}$, angle of flexure of the processed shaft $\bar{U}(\bar{x}, \bar{t})$.

The analytical model embraces all the mentioned kinds of technological defects (Table 1). Researching the first and the fourth kinds of technological defects the bearer 3 is not taken into account.

Below one can see the method of researching stability of the mathematical model.

The equation of free oscillations of a non-rigid shaft is as follows:

$$
E J \frac{\partial^{4} \overline{U_{i}}}{\partial \bar{x}^{4}}+m \frac{\partial^{2} \overline{U_{i}}}{\partial t^{-2}}=0,
$$

where EJ - rigidity of the processed shaft at the flexure; $\bar{U}$ - the flexure of the processed shaft, $\mathrm{m}$ - mass of a unit of shaft length.

In the cutting process the cutter excites a perturbing force which is applied in some intermediate section of the shaft dividing the length in two parts.

Thus it is necessary to determine eight constants from the four conditions at the ends of the shaft and four conditions of connection.

The conditions of connection are the following:

$$
\begin{gathered}
\bar{U}_{1}\left(\bar{x}_{0}, \bar{t}\right)=\bar{U}_{2}(0, \bar{t}), \\
\bar{U}_{1}^{\prime}\left(\bar{x}_{0}, \bar{t}\right)=\bar{U}_{2}^{\prime}(0, \bar{t}), \\
\bar{U}_{1}^{\prime \prime}\left(\bar{x}_{0}, \bar{t}\right)=\bar{U}_{2}^{\prime \prime}(0, \bar{t}), \\
E J\left(\bar{U}_{1}^{\prime \prime \prime}\left(\bar{x}_{0}, \bar{t}\right)-\bar{U}_{2}^{\prime \prime \prime}(0, \bar{t})\right)= \\
=\overline{F_{p}}-\left(m_{3} \bar{U}_{2}^{\prime \prime}(0, \bar{t})+h_{3} \bar{U}_{2}^{\prime}(0, \bar{t})+C_{3} \bar{U}_{2}(0, \bar{t})\right)
\end{gathered}
$$

where U1 means a flexure on the part from the left end of the shaft $(x=0)$ to the cutter $\left(x=\bar{x}_{0}\right)$, i. e. at the interval $\left[0, \bar{x}_{0}\right]$, and $\mathrm{U}_{2}$ means a flexure on the part from the cutter to the right end of the shaft, i. e. at the interval $\left[\bar{x}_{0}, l\right], \mathrm{m}_{3}, \mathrm{~h}_{3}, \mathrm{C}_{3}$ - parameters which characterize the outfit in the cutting zone.

The cutting power is expressed by the equation:

$$
\bar{F}_{p}=K^{(1)} \bar{U}_{1}\left(\bar{x}_{0}, \bar{t}\right)-K^{(2)} \bar{U}_{2}\left(\bar{x}_{0}, \bar{t}-\bar{\tau}\right),
$$

where $\tau$ is a rotation period of the shaft (lag time); $\mathrm{K}^{(1)}$, $\mathrm{K}^{(2)}$ is dynamic characteristics of cutting of the first and second type.

The first three equations in conditions of connection mean continuity of a bending curve of the shaft (flexure), the angle of flexure of the shaft's profile, and the moment of flection in the force point of cutting power, accordingly. The fourth equation means the jump of function of transverse force in the given profile by the amount characterized by the following equation:

$$
\bar{F}_{p}-\left(m_{3} \bar{U}_{2}(0, t)+h_{3} \bar{U}_{2}(0, t)+C_{3} \bar{U}_{2}(0, \bar{t})\right)
$$

The boundary data are the following:

$$
\begin{gathered}
\bar{U}_{1}^{\prime \prime}(0, t)=0, \\
-E J \bar{U}_{1}^{\prime \prime \prime}(0, t)=
\end{gathered}
$$




$$
\begin{gathered}
=m_{1} \bar{U}_{1}^{\prime \prime}(0, \bar{t})+h_{1} \bar{U}_{1}^{\prime}(0, t)+C_{1} \bar{U}_{1}(0, \bar{t}), \\
\bar{U}_{2}^{\prime \prime}\left(l-\bar{x}_{0}, \bar{t}\right)=0, \\
\\
E \bar{U}_{2}^{\prime \prime \prime}\left(l-\bar{x}_{0}, \bar{t}\right)=m_{2} \bar{U}_{2}^{\prime \prime}\left(l-\bar{x}_{0}, \bar{t}\right)+ \\
+h_{2} \bar{U}_{2}^{\prime}\left(l-\bar{x}_{0}, t\right)+C_{2} \bar{U}_{2}\left(l-\bar{x}_{0}, \bar{t}\right) .
\end{gathered}
$$

To bring the system (1-4) to dimensionless form let us consider the following change of variables:

$$
x=\frac{\bar{x}}{l-\bar{x}_{0}}, U=\frac{\bar{U}}{T}, t=\frac{\bar{t}}{\tau} .
$$

Let us introduce:

$$
\begin{gathered}
A=\frac{E J}{\left(l-\bar{x}_{0}\right)^{4}}, \quad B=\frac{m}{\tau^{2}}, \quad \alpha=\sqrt{\frac{A}{B}}, \\
m_{1,2,3}=\frac{m_{1,2,3}}{A\left(l-\bar{x}_{0}\right) \tau^{2}}, \quad C_{1,2,3}=\frac{C_{1,2,3}}{A\left(l-\bar{x}_{0}\right)}, \\
h_{1,2,3}=\frac{h_{1,2,3}}{A\left(l-\bar{x}_{0}\right) \tau}, \\
P \div \frac{d}{d t}, \quad q \div \frac{d}{d x}, \\
V_{1,2,3}^{(p)}=\left(m_{1,2,3} p^{2}+h_{1,2,3} p+C_{1,2,3}\right) .
\end{gathered}
$$

Using Laplase transformation to the system of equation at zero initial condition let us pay attention to the figuring class according to variables $\mathrm{x}$ and $\mathrm{t}$, step by step. With the equation (1) we obtain:

$$
\begin{gathered}
U(q, p)=\frac{q^{4}}{q^{4}+4 \alpha^{4}} \cdot U(o, p)+ \\
+\frac{q^{3}}{q^{4}+4 \alpha^{4}} \cdot U^{\prime}(o, p)+\frac{q^{2}}{q^{4}+4 \alpha^{4}} \cdot U^{\prime \prime}(o, p)+ \\
+\frac{q}{q^{4}+4 \alpha^{4}} \cdot U^{\prime \prime \prime}(o, p), \\
4 \alpha=\frac{m\left(l-\bar{x}_{0}\right)^{4}}{E J \cdot \tau^{2}} \cdot p^{2} .
\end{gathered}
$$

Let us express the original of the function $U(q, p)$ according to the variable $\mathrm{q}$ as follows:

$$
\begin{gathered}
U(x, p)=y_{1}(\alpha, x) \cdot U(o, p)+ \\
+\frac{y_{2}(\alpha, x)}{\alpha} \cdot U(o, p)+ \\
+\frac{y_{3}(\alpha, x)}{\alpha^{2}} \cdot U^{\prime \prime}(o, p)+\frac{y_{4}(\alpha, x)}{\alpha^{3}} \cdot U^{\prime \prime \prime}(o, p) .
\end{gathered}
$$

where $\mathrm{y}_{1}(\mathrm{t}), \mathrm{y}_{2}(\mathrm{t}), \mathrm{y}_{3}(\mathrm{t}) \mathrm{y}_{4}(\mathrm{t})$ are Krylov functions.
Putting the equation (6) in limited conditions and in conjugating conditions, and using the properties of Krylov functions $\mathrm{Y}_{1}(0)=1, \mathrm{y}_{2}(0)=\mathrm{y}_{3}(0)=\mathrm{y}_{4}(0)$, we shall get a linear system of algebraic equations in relation with $U_{1}(o, p), \quad U_{1}^{\prime}(o, p), \quad U_{1}^{\prime \prime}(o, p), \quad U_{1}^{\prime \prime \prime}(o, p)$, $U_{2}(o, p), U_{2}^{\prime}(o, p), U_{2}^{\prime \prime}(o, p), U_{2}^{\prime \prime \prime}(o, p)$ as follows:

$$
\begin{gathered}
U_{1}^{\prime \prime}=0, \\
U_{1}^{\prime \prime \prime}+U_{1} V_{1}=0, \\
-4 \alpha^{2} y_{3}(\alpha) U_{2}-4 \alpha^{2} y_{4}(\alpha) U_{2}^{\prime \prime}+ \\
+\frac{y_{2}(\alpha)}{\alpha} U_{2}^{\prime \prime \prime}=0, \\
{\left[4 \alpha^{3} y_{3}(\alpha)+y_{1}(\alpha) V_{2}\right] \cdot U_{2}+} \\
+\left[4 \alpha^{2} y_{3}(\alpha)+\frac{y_{2}(\alpha) V_{2}}{\alpha}\right] \cdot U_{2}^{\prime}+ \\
+\left[4 \alpha^{2} y_{4}(\alpha)+\frac{y_{3}(\alpha) V_{2}}{\alpha^{2}}\right] \cdot U_{2}^{\prime \prime}+ \\
+\left[-y_{1}(\alpha)+\frac{y_{4}(\alpha) V_{2}}{\alpha^{3}}\right] \cdot U_{2}^{\prime \prime \prime}=0 \\
y_{1}\left(\alpha, x_{0}\right) \cdot U_{1}+\frac{y_{2}(\alpha, x)}{\alpha} \cdot U_{1}^{\prime}+ \\
+\frac{y_{4}\left(\alpha, x_{0}\right)}{\alpha^{3}} \cdot U_{1}^{\prime \prime \prime}-U_{2}=0, \\
-4 \alpha y_{4}\left(\alpha, x_{0}\right) \cdot U_{1}+y_{1}\left(\alpha, x_{0}\right) \cdot U_{1}^{\prime}+ \\
+\frac{y_{3}\left(\alpha, x_{0}\right)}{\alpha^{2}} \cdot U_{1}^{\prime \prime}-U_{2}^{\prime}=0 \\
-4 \alpha^{2} y_{3}\left(\alpha, x_{0}\right) \cdot U_{1}-4 \alpha y_{4}\left(\alpha, x_{0}\right) \cdot U_{1}^{\prime}+ \\
+\frac{y_{2}\left(\alpha, x_{0}\right)}{\alpha} \cdot U_{1}^{\prime \prime \prime}-U_{2}^{\prime \prime}=0, \\
+4 \alpha^{3} y_{2}\left(\alpha, x_{0}\right) \cdot U_{1}-4 \alpha^{2} y_{3}\left(\alpha, x_{0}\right) \cdot U_{1}^{\prime}+ \\
+y_{1}\left(\alpha, x_{0}\right) \cdot U_{1}^{\prime \prime \prime}+V_{3} U_{2}-U_{2}^{\prime \prime \prime}=F_{p}
\end{gathered}
$$

Fp is determined this way:

$$
F_{p}=\left[\begin{array}{c}
K_{2}^{(1)} \cdot \sin ^{2} \beta+0,5 K_{3}^{(1)} \cdot \cos 2 \beta- \\
-\left(K_{2}^{(2)} \cdot \sin ^{2} \beta+0,5 K_{3}^{(2)} \cdot \cos 2 \beta\right) \cdot e^{-P t}
\end{array}\right] \times
$$

here $K_{2,3}^{(1),(2)}$ means the given dynamic characteristics of cutting (DCC); $\mathrm{H}$ - means tap depth at which the DCC were taken; $\beta$ - the angle of slope of vibration direction of the processed shaft at taking DCC characteristics.

Substituting the results obtained using the system of equations according to Cramer rule for $U_{1}(o, p)$, $U_{1}^{\prime}(o, p), U_{1}^{\prime \prime}(o, p), U_{1}^{\prime \prime \prime}(o, p)$ into the equation (7) we can find the characteristic equation for the dynamic system under research: 


$$
1-\frac{\Phi\left(p, x_{0}\right)}{\Delta\left(p, x_{0}\right)} \cdot F_{p}=0
$$

where $\Delta\left(\mathrm{p}, \mathrm{x}_{0}\right)$ means a characteristic equation for an open-loop system.

$$
\begin{gathered}
\Phi\left(p, x_{0}\right)=y_{1}\left(\alpha, x_{0}\right) \cdot A_{1}+ \\
+\frac{y_{2}\left(\alpha, x_{0}\right)}{\alpha} \cdot A_{2}+\frac{y_{4}\left(\alpha, x_{0}\right)}{\alpha^{3}} \cdot A_{3},
\end{gathered}
$$

with A1, A2, A3 as algebraic additions of the corresponding elements of the matrix got from the system of equations (7). The research is described in the works [10-15].

\subsection{The research of stability zones for different kinds of equipment of a turning lathe}

At lathe work with non-rigid shafts, in order to research the influence of different kinds of technological equipment of a turning lathe on vibration-resistance, it is the most convenient and economical to use the method of successive parameters identification of the worked out mathematical model which is limited by the process of restricted oblique cutting.

Choosing $\mathrm{W}=-1 / \mathrm{H}$ as the complex parameter on the basis of which the curve of D-division is drawn, it is possible to find the depth cutting limit for different outfit. The calculations presented are made with the help of a complex of programs where the method of stability calculation in "the minor" is used according to the following algorithm.

1. For calculating the transfer function for each value of angular rate on a complex plane ( $\mathrm{ReW}, \mathrm{JmW})$ a hodograph of the transfer function of the researched system is made (Pic. 2).

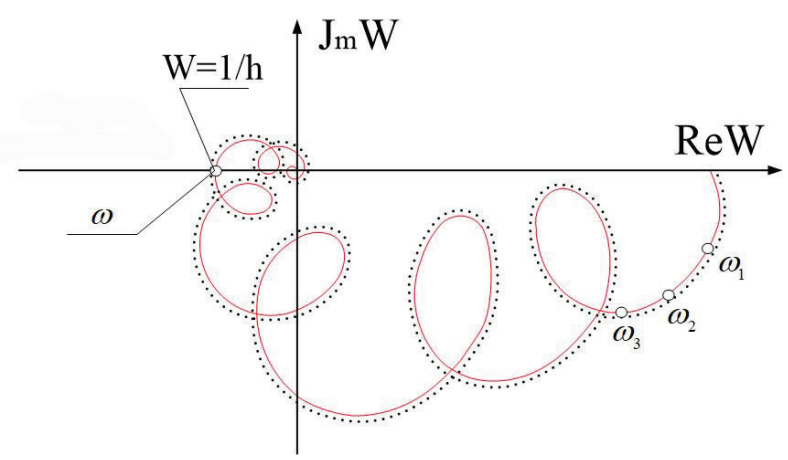

Fig.2 The curve of D-division for determinig the stability area "in the minor"

2. The points of crossings of the hodograph with the real axis ReW are stated, to do that the imaginary parts $W(p)$ are compared in sign at different values of angular rate $\omega$ and $\omega+K$ following each other, where $K$ is a spacing. They are compared until the moment when the imaginary parts have different signs. For the point of hodograph and ReW crossing the arithmetical average of the real parts of the function in the corresponding points is taken.
3. Having found all the crossing points of the hodograph and the real axis ReW one should choose the point that is the most remote from the central point of coordinates. It is the boundary of the stability area in "the minor", and the corresponding value of cyclic frequency is the frequency of excitation of authoroscillations.

The value of the limit cutting depth for stability in "the minor" which is calculated for all the kinds of the outfit under researched (Table 1).

In the table: 1 means processing with the help of a lathe self-centering chuck with contraction by the rear turning centre; 2 means processing in the centres with driving equipment; 3 means processing in a lathe selfcentering chuck with cam readjustment with contractor by the rear turning centre with readjustment; 4 means processing in the leading riffled centre with contraction by the rear rotating centre with readjustment; 5 means the same as 4 but using a steady vibration suppressor which is moving along the axis of the processed component.

Table 1. The data of the limit cutting depth which correspond stability "in the minor"

\begin{tabular}{|c|c|c|}
\hline \multirow{2}{*}{ The variant of outfit } & \multicolumn{2}{|c|}{ The limit cutting depth (mm) } \\
\cline { 2 - 3 } & modeling & experiment \\
\hline 1 & 0,138 & 0,15 \\
\hline 2 & 0,124 & 0,1 \\
\hline 3 & 0,164 & 0,15 \\
\hline 4 & 0,09 & 0,1 \\
\hline 5 & 4,61 & 5 \\
\hline
\end{tabular}

\section{Conclusion}

The following results were obtained in the research:

1. Methods of stating the stability zone of a dynamic system at sharpening non-rigid shafts with different outfit were worked out.

2. A characteristic equation for calculating the limit cutting depth by means of ECM was got.

3. By means of the worked-out mathematical model the boundaries of stability zones for different types of outfits of a lathe machine were stated.

The methods of researching vibration-resistance of linear turning of non-rigid shafts let reflect complex dynamic processes in a closed-loop system of a lathe machine more objectively. With the help of a mathematical model it is possible to determine the boundaries of the stability zones at intensive lathe processing of non-rigid shafts, to find out the connection between stability zones, the technological system machine-device-tool-blank, and the limit cutting depth with different outfits of a lathe machine. On the basis of the analysis it is possible to give important practical recommendations. 


\section{References}

1. V.A. Kudinov, Machine Dynamics (Moscow, 1967)

2. S.L. Vasilevykh, L.A. Vasilevykh, System technology (Dnepropetrovsk, 2009)

3. S.L. Vasilevykh, V.E. Saitov, Features of processing of nonrigid shafts, Modern scienceintensive technologies № 11, pp. 67-68 (2012)

4. S.L Vasilevykh, V.E. Saitov, Technological means for ensuring the vibration resistance of the process of turning non-rigid shafts, Modern high technology, №3, pp. 7-10 (2014)

5. S.L. Vasilevykh, All-Russian annual scientific and practical conference Society, Science, Innovations: Sat. Materials, Vyatka State University (Kirov: VyatGU, 2014), pp. 1556-1560

6. X. Han, H. Ouyang, M. Wang, Y. Mao, N. Hassan, Selfexcited vibration of workpieces in a turning process, Proceedings of the Institution of Mechanical Engineers, Part C: Journal of Mechanical Engineering Science, № 226(8s), pp. 1958-1970 (2012)

DOI: $10.1177 / 0954406211435880$

7. V.N. Poduraev, Machining with vibrations (Moscow, 1970)

8. C.F. Bisu, P. Darnis, A. Gérard, J-Y. K'nevez, Displacements analysis of self-excited vibrations in turning, The International Journal of Advanced Manufacturing Technology 44(1s), pp. 1-16 (2008) DOI: $10.1007 / \mathrm{s} 00170-008-1815-8$

9. C.F. Bisu, A. Gérard, J-Y K'nevez, R. Laheurte, O. Cahuc, Self-excited vibrations in turning: Forces torsor analysis. The International Journal of Advanced Manufacturing Technology 44, pp. 447462 (2009) DOI: 10.1007/s00170-008-1850-5

10. S.L. Vasilevykh, A.V. Ivanaysky, The choice of the design model of the elastic system of the machine with various technological equipment. Technology of mechanical engineering, № 7, pp. 23-26 (2013)

11. S.L Vasilevykh, V.E. Saitov, Research of vibrostability in plane turning of non-rigid shafts (Saarbruken, Germany, LAMBERT Academic Publiahing, 2012)

12. Yu.I. Gorodetsky, V.Ya. Prodiu, Experimental determination of the dynamic characteristics of the cutting process with the aid of a computer, Machines and tools 6, pp. 25-27. (1980),

13. Yu.I. Gorodetsky, A.S. Budankov, V.N. Komarov, On a system of the experimental study of the dynamics in the process of cutting metals. Problems of mechanical engineering and reliability of machines, RAS, 1, pp. 80-86 (2008)

14. S.L. Vasilevykh, A.P. Galkin, Yu.I. Gorodetsky, Mathematical modeling and the study of the stability of non-rigid plane turning of shafts with different technological support, Univer collection of scientific papers Mathematical Modeling and Optimization, pp. $42-50$ (1991)
15. O.A.Yamnikova, Construction of mathematical models of non-rigid shaft vibrations in cutting, STIN 1, pp. 18-21 (2003) 